\title{
SEISMIC BASE ISOLATORS FOR A SILO SUPPORTING STRUCTURE
}

\begin{abstract}
DANIEL BîTC $\breve{A}$ - Lecturer, PhD, Technical University of Civil Engineering, Faculty of Civil Engineering,
\end{abstract} e-mail: bitca@utcb.ro

EMILIAN URSU - PhD c. Eng., Technical University of Civil Engineering, Faculty of Civil Engineering, e-mail: emilian.ursu@p-c.ro

PAUL IOAN - Assoc. Professor, PhD, Technical University of Civil Engineering, Faculty of Civil Engineering, e-mail:paul@p-c.ro

\begin{abstract}
A 3000 tones capacity silo, located in a seismic area with ground acceleration $\mathrm{a}_{\mathrm{g}}=0,20 \mathrm{~g}$ and $\mathrm{T}_{\mathrm{C}}=1,0 \mathrm{~s}$, was designed in a classical solution The supporting structure has an octagonal shape in planview, and columns with "Maltese cross sections". The main lateral resisting system is made up of centric bracings with cross-section class I.

The technological project has required two silos and the solution was to support them on a common raft foundation. The stresses and strains due the seismic action led to material consumption that exceeded the agreed budget. In order to reduce the costs, two versions of isolator positions were studied: base isolators (at the connection between infrastructure and superstructure) and at the silo's bearing level on the supporting structure.

A number of eight vertical seismic isolators were used and in order to limit the horizontal displacements due to wind action and for small intensity earthquakes special devices were introduced

Comparing the state of stresses and deformations and also the cost analysis regarding the positioning of the isolators, the second solution was chosen as the most feasible.
\end{abstract}

Keywords: base isolation, isolators, dampers, seismic response.

\section{Introduction}

In the classical design process, in case of a major seismic event, degradations of the structural and non-structural elements will occur. This fact involves post-earthquake repair and consolidation works. Considering the reference return period for the earthquake indicated in the design code $(\mathrm{TNCR}=225$ years - according to P100-1/2013) reported to the lifetime of a building, the classical design proves to be more advantageous in terms of initial cost for civil and industrial low-rise constructions.

A modern method of reducing the effects of seismic action on the structure is the base isolation method. In case of a major seismic event, there is no degradation of the structural and nonstructural elements, but the method involves a much higher initial cost. One of the major advantages of the base isolation system is that it ensures the continuous operation of the building and the intervention works are limited only to the isolation layer.

The method of base isolation involves the insertion between the ground and structure base of an isolating layer that isolates the building movement from the ground motion and it is based on the following reasoning: an infinite rigid structure has the vibration period equal to 0 , and during the seismic action the maximum acceleration induced will be equal to the peak ground acceleration (PGA). Thus, there will be no relative movement between the structure and the ground. In case of a very flexible structure, the vibration period tends to infinity. For this type of structures the acceleration induced during the seismic action is 0 , but between the structure and the ground relative displacements occur that tend toward maximum ground displacement (PGD). The resistance structure of buildings is placed between the two presented cases. 
The principle of the method consists in the fact that for a rigid construction, having its fundamental period of vibration corresponding to the maximum amplification area in the elastic response spectrum, through the introduction of the isolating layer, the structure is more flexible, the vibration period increases significantly and the effects of the seismic action are diminished"the period shift effect". The isolation system is considered efficient if the ratio between the period of the isolated structure and the non-isolated one is bigger than 3.

The base isolation method is more efficient for high mass structures. In case of light structures, in order to achieve the target isolation period, a reduced amount of rigidity should be adopted.

$$
T=2 \pi \sqrt{\frac{M}{K}}
$$

Certain types of isolators have minimum dimensions which ensure their stability under lateral actions, while for small geometrical dimension, the design process becomes difficult. For light structures, an alternative is the adoption of the friction isolation systems that do not have this restriction.

The base isolation method is efficient for low-rise structures and where lateral movements are possible, because the system works with large lateral displacements. Additionally, in the design process of the isolation system, the following aspects must be considered:

- seismic conditions of the site: it will be ensured that the isolated vibration periods do not correspond to the amplification area of the elastic response spectrum or resonance with the foundation soil;

- soil conditions: the isolation system works very well on stiff soils, but on soft soils the efficiency decreases;

- local effects - "near fault" caused by the proximity of the fault and the "fling effect" may occur;

- the state of stress: the isolators have a low tensile strength, and the failure corresponding to this type of stress is fragile.

In terms of cost, the method of base isolation applied to the new constructions is less expensive than applied to the existing buildings.

\section{Base isolation system components}

The isolation layer consists of seismic isolators and necessary dampers. The isolators have large vertical stiffness to ensure the secure transmission of gravitational loads and a reduced lateral stiffness to achieve the isolation of the seismic motion. The ratio of the two rigidities ranges between 2500 and 3000 . The main types of isolators are the following:

- natural rubber bearings (NRB);

- lead rubber bearings (with lead core LRB);

- $\quad$ high damping rubber bearings (HDRB)

- $\quad$ sliding bearings (SB);
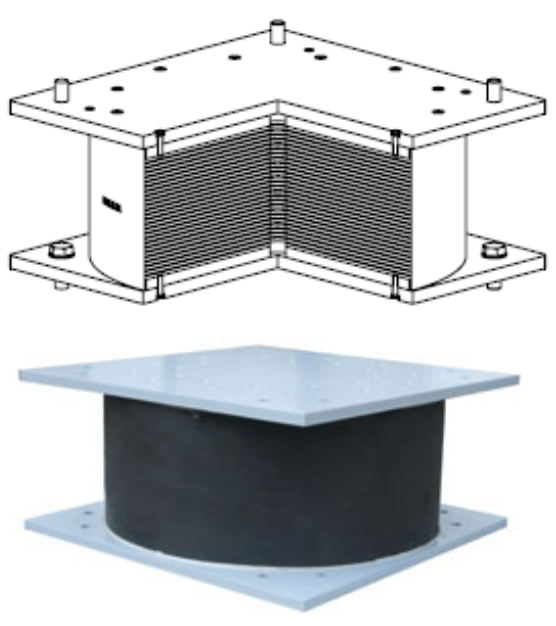

Fig. 1 - Isolator type HDRB

The HDRB isolator (figure 1) consists of several layers of synthetic rubber of 3-10mm thickness, with damping properties and which is interposed between steel plates of $2.5-4 \mathrm{~mm}$. These 
isolators are manufactured with diameters ranging between $500-1500 \mathrm{~mm}$, but usually diameters ranging between $600-1200 \mathrm{~mm}$ are used. The main parameters of the isolator are the shape factors $S_{1}$ and $S_{2}$ respectively. The shape factor $S_{1}$ represents a dimensionless value of the shape ratio for a single layer of rubber; in case of a circular isolator with diameter $D$ and the thickness of the rubber layer $t_{R}$ this ratio is:

$$
S_{1}=\frac{D}{4 \cdot t_{R}}
$$

The value of this ratio is between 35 and 40 . The shape factor $S_{2}$ represents the ratio between the isolator diameter $D$ and the total thickness of the rubber layer $T_{q}$. The value of this ratio is about 5. The unitary compression stress produced by long term loads is about $10-15 \mathrm{~N} / \mathrm{mm}^{2}$ and the unitary compression stress produced by short term loads is $15-20 \mathrm{~N} / \mathrm{mm}^{2}$. Design deformations of these isolators are $250-300 \%$ and the ultimate strain is $400 \%$. Due to the creep, aging phenomenon, temperature effects, load history, frequency of loading and unloading cycles, a decrease of $20 \%$ in the isolator parameters can occur in time. For a lateral displacement of $300 \%$ an equivalent viscous damping of about $20 \%$ is obtained. Dampers are disposed to reduce the relative displacements at the isolation layer and to stop the motion.

The main types of dampers are hydraulic dampers (provide viscous damping), lead dampers and steel dampers (provide hysteretic damping).

\section{Description of the analyzed structure}

The analyzed structure in this article is a silo with steel structure used to store limestone powder which will be located in the Oltenia Energy Complex, Craiova Subsidiary, Dolj County. The silo consists of a storage cell with a volume of $3800 \mathrm{~m}^{3}$ and a total capacity of 4940 tonnes and a centrically braced support structure, with " $\mathrm{X}$ " and inverted "V" shape diagonals. The composition of the structure is shown in the following figure:

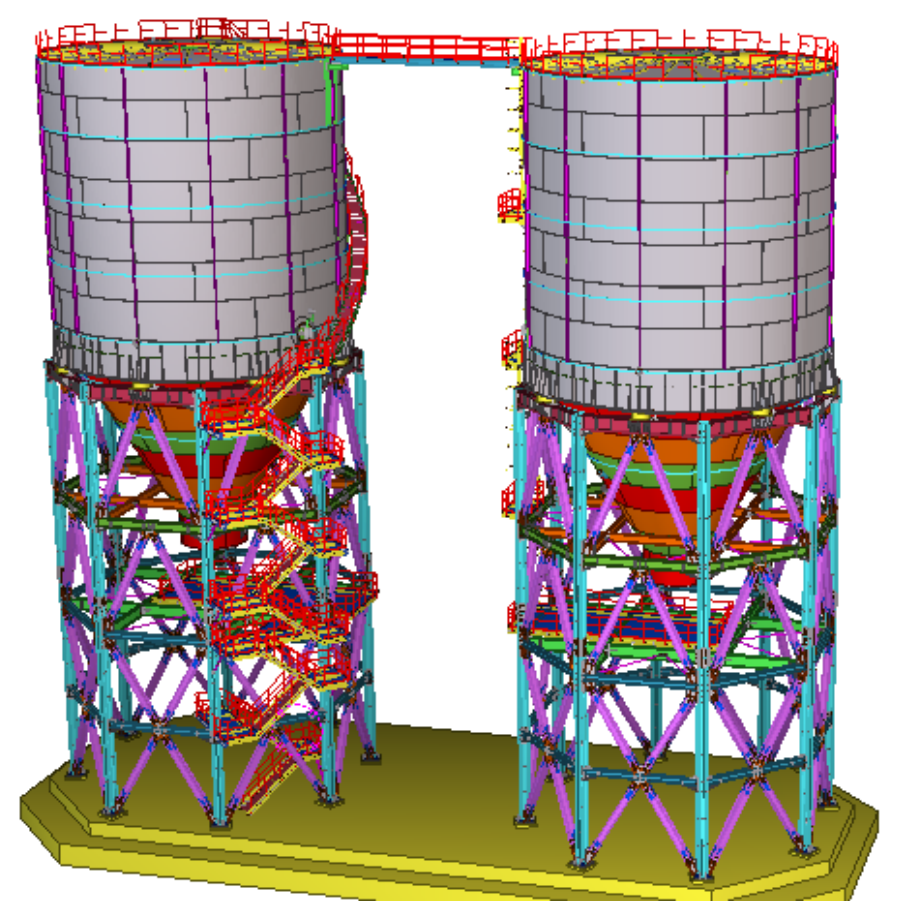

Fig. 2 -The composition of the analyzed structure

The storage cell consists of a cylindrical part with a diameter $\mathrm{D}=15.30 \mathrm{~m}$ and a height of $\mathrm{H}=15.80 \mathrm{~m}$, and a discharge funnel provided at the inferior part. The funnel has an angle of $60^{\circ}$ and a height of $\mathrm{h}=12.25 \mathrm{~m}$. The bearing of the storage cell on the support structure is made in eight points. 
The support structure has eight columns made of two HEA500 profiles with „Maltese crosssection" and are radial arrayed at an angle of $45^{\circ}$. The braces are made of rectangular hollow section and the intermediate beams are made of rolled profiles HEA 300 and HEA 450, depending on the stress state. The beams from the top of the support, which support the storage cell are made in welded solution and have a height of $700 \mathrm{~mm}$.

\section{Structural analysis and the FEM model}

\subsection{Load assessment}

The assessment of the seismic action for the analysed structure was performed in accordance with the normative: P100-1/2013-"Seismic Design Code-Part I: Design provisions for buildings". The construction site is characterized by a peak ground acceleration of $\mathrm{a}_{\mathrm{g}}=0.20 \mathrm{~g}\left(\mathrm{~T}_{\mathrm{NCR}}=225\right.$ years) and a control period of the response spectrum (corner period) of $\mathrm{T}_{\mathrm{C}}=1.0 \mathrm{~s}$.

The assessment of the dynamic wind action was performed in accordance with the design norm CR 1-1-4:2012 - "Design Code. Evaluation of wind action on buildings".

The structural analysis model was developed in SAP2000, a computer program that is based on the finite element method. Linear finite elements were used for modelling of the steel support frame and shell elements were used for the circular plates of the storage cell surface.

\subsection{The structural analysis model in classical design}

In classical design, in the structure sizing process only a fraction of the seismic action is taken into account, while the rest of it is dissipated by certain structural elements that will work in the post-elastic domain. In case of the analyzed structure, energy can be dissipated only in the support structure; the walls of the cell storage consists of circular curved plates with thicknesses between 8 and $20 \mathrm{~mm}$ capacity and with very low dissipation.

The behavior factor for the structure was chosen $\mathrm{q}=2$, corresponding to a medium ductility class, because the structure is an inverted pendulum, even if the bracing system is centred. After the modal analysis was completed, it resulted that the first two modes of vibration are translation modes and its next mode is torsion. It also resulted that the first two modes of vibration are correlated modes having their fundamental vibration period $\mathrm{T}_{1}=0.8089 \mathrm{~s}$ and $\mathrm{T}_{2}=0.8087 \mathrm{~s}$.

Thus, using modal response spectrum method, CQC (complete quadratic combination) was chosen for composing the modal responses in order to determine the state of stress in the structural elements.

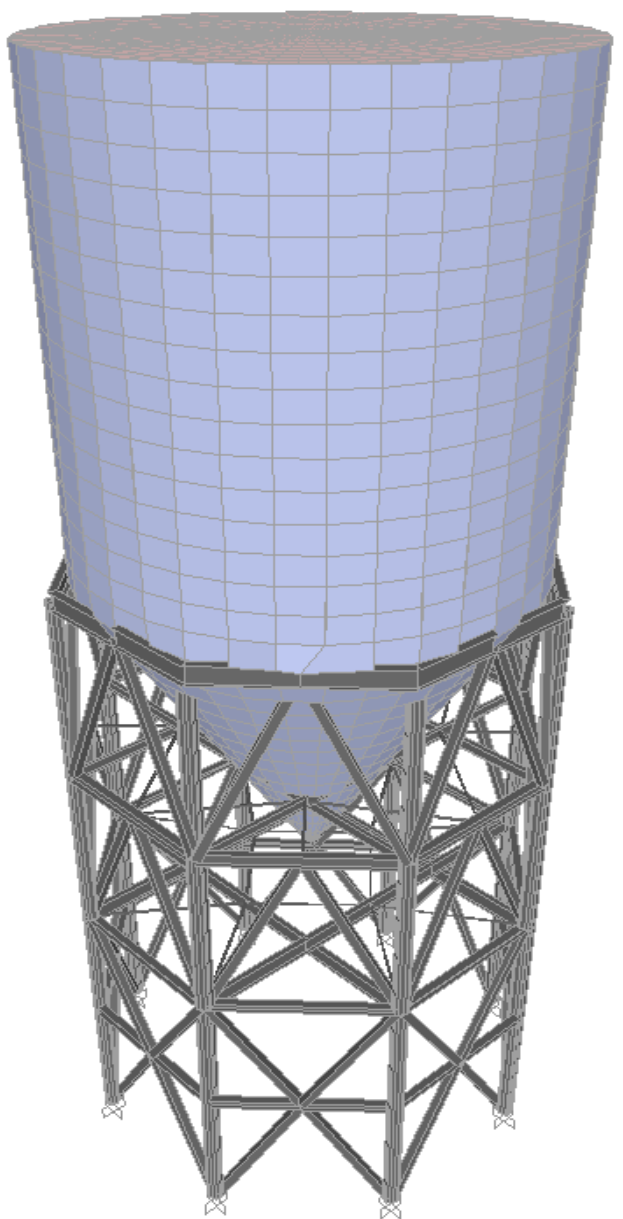

Fig. 3 - Structural analysis model for $\mathrm{q}=2$ 


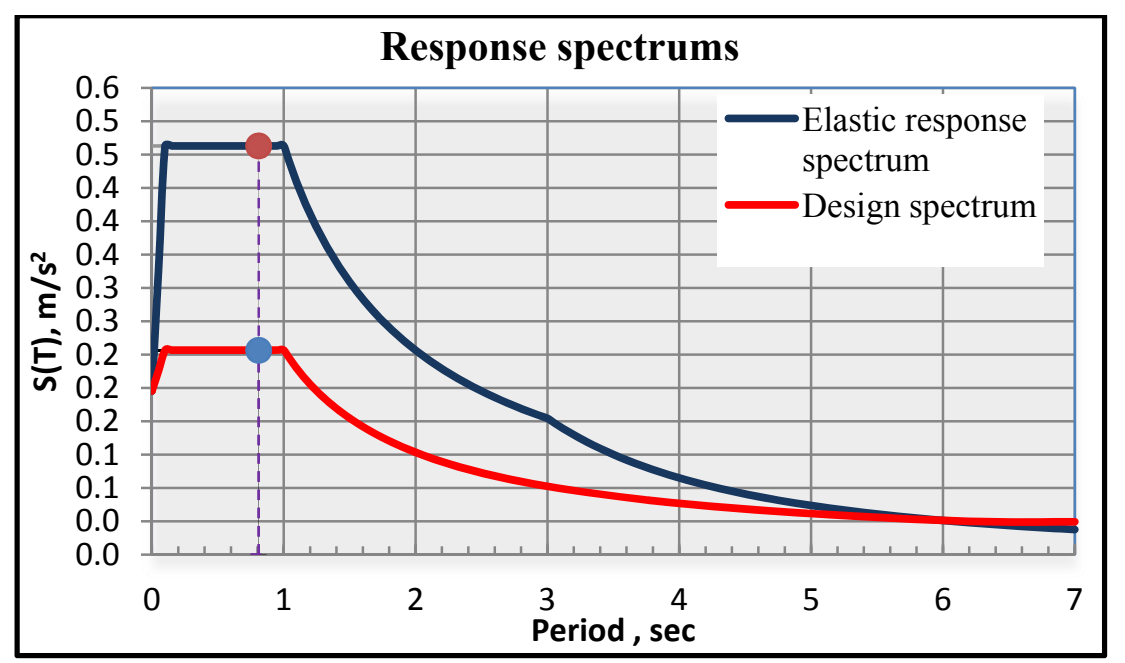

Fig. 4 - Elastic response spectrum and design spectrum respectively, for $\mathrm{q}=2(\zeta=0,05)$

It can be observed, from the visual analysis of the spectral response charts, that the limestone silo structure is located in the maximum amplification area. The maximum lateral displacement at the top of the structure, under the seismic action has a value of $\delta=68.5 \mathrm{~mm}$. The base shear force resulted from seismic action is about $F_{b}=9530 \mathrm{kN}$ and the dynamic wind action generates a total lateral force of $F_{v}=1120 \mathrm{kN}$. The total weight of the steel support structure in the assumption of traditional design will lead to a value of $G_{s} \approx 250$ tons.

\subsection{The structural analysis model in base isolation method}

In most cases, when this method is adopted, the isolation layer is placed at the base of the structure- civil buildings case. However, there are some situations, where it is more convenient to isolate only a certain amount of mass, especially in case of industrial structures with lumped mass. For the analyzed structure we opted for the arrangement of isolation layer on top of the steel support, under the storage cell bearings point.

The adopted isolation system consists of HDRB isolators with a diameter of $D=850 \mathrm{~mm}$. The isolator consist of synthetic rubber plates with damping properties and a thickness of $\mathrm{t}=8 \mathrm{~mm}$, which are interposed between the steel plates with a thickness of $\mathrm{ts}=3 \mathrm{~mm}$. The isolators equivalent viscous damping is about $\beta$ eff $=10 \%$.

For this structure, the possibility of seismic isolation was taken into account because it is located within a power plant (importance class I - according to P100-1/2013) and the continuous operation is obligatory.

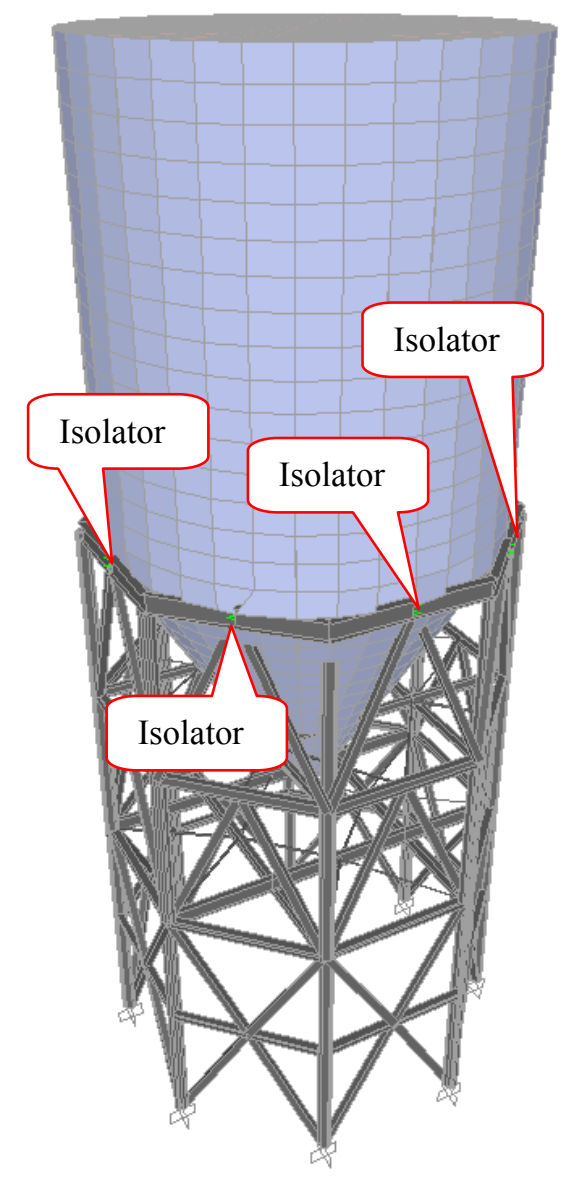

Fig. 5 - Structural analysis model with isolators placed under the storage cell 
The analyzed silo is an inverted pendulum structure, with the weight suspended at a certain height. In case of a seismic motion, the indirect effect has a major contribution to the values of the axial forces in the columns of the steel support. This indirect effect puts certain columns in tension, while others are heavily compressed. In these circumstances it is difficult to design the isolation system, given that the isolators have low tension capacity and failure is fragile. On the other hand, for a stable behaviour of the system the uniform unitary compression stress, may not exceed $20 \mathrm{~N} / \mathrm{mm}^{2}$.

A compromise solution was the disposition of the isolation system between the storage cell and the steel support, given that the $91 \%$ of the total weight of the structure is located above this steel support.

The modelling of isolators in the FEM computer program was performed with link elements with a linear behaviour. The linear behaviour of the isolators and the effective stiffness $K_{\text {eff }}$ value was guaranteed by the manufacturer. For each translation direction, the effective stiffness has the following value:

$$
\mathrm{K}_{\mathrm{eff}}=1,09 \mathrm{kN} / \mathrm{mm}
$$

Fig. 6 - Detail for seismic isolator under the storage silo cell

In the structural analysis model, at each bearing point of the cell storage on the steel support structure, a link element was introduced, considered very stiff in the vertical direction and in the horizontal direction it has the rigidity $-K_{\text {eff }}$.

After performing the modal analysis we obtained that the first two modes of vibration are translation modes and the next mode is torsion.

A very important aspect in the seismic isolation method is the proper arrangement of the isolators and dampers. They shall always be placed so that there is no torsion. Just as in the classical design, it resulted that the first two modes of vibration are correlated modes with the fundamental vibration period of $T_{1}=3.7815 \mathrm{~s}$.
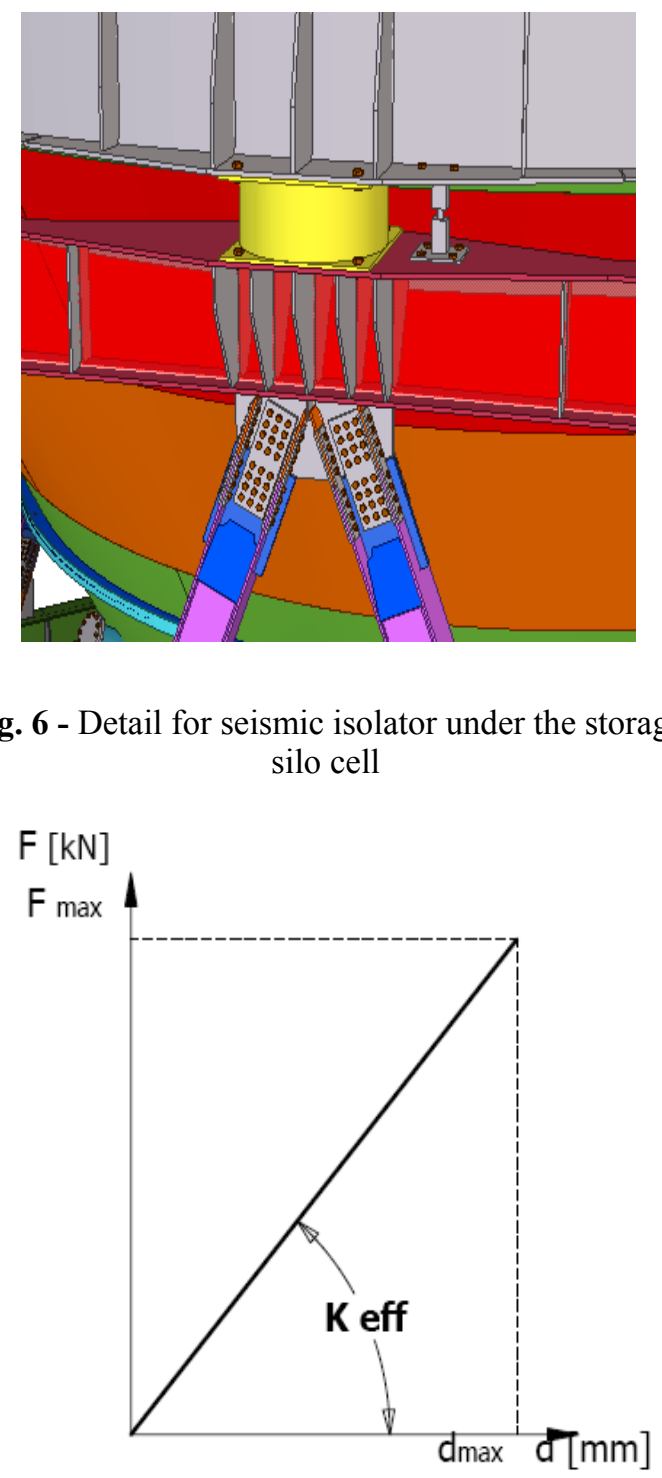

Fig. 7 - Biliniar model of the isolators

$$
\frac{T_{1, \text { izolat }}}{T_{2, \text { neizolat }}}=\frac{3.7815}{0.8089}=4.67
$$

From the analysis of the normalized elastic response spectrum $\beta(t)$ - figure 8 , it can be seen that the dynamic amplification factor decreased from a maximum value of 2.50 to a value of 0.524 . Once reducing the dynamic amplification factor, the effects of the seismic action on the structure are reduced. This reduction represent the idea of seismic isolation method. 


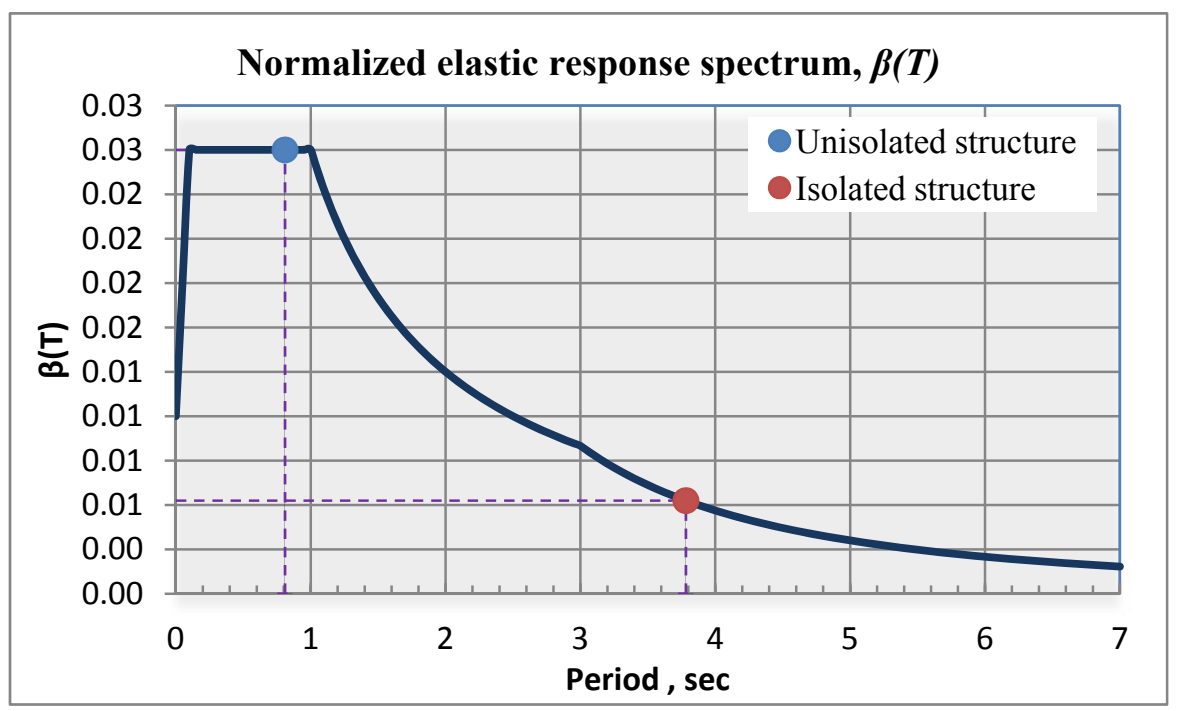

Fig. 8 - Normalised elastic response spectrum, $\beta(T)$

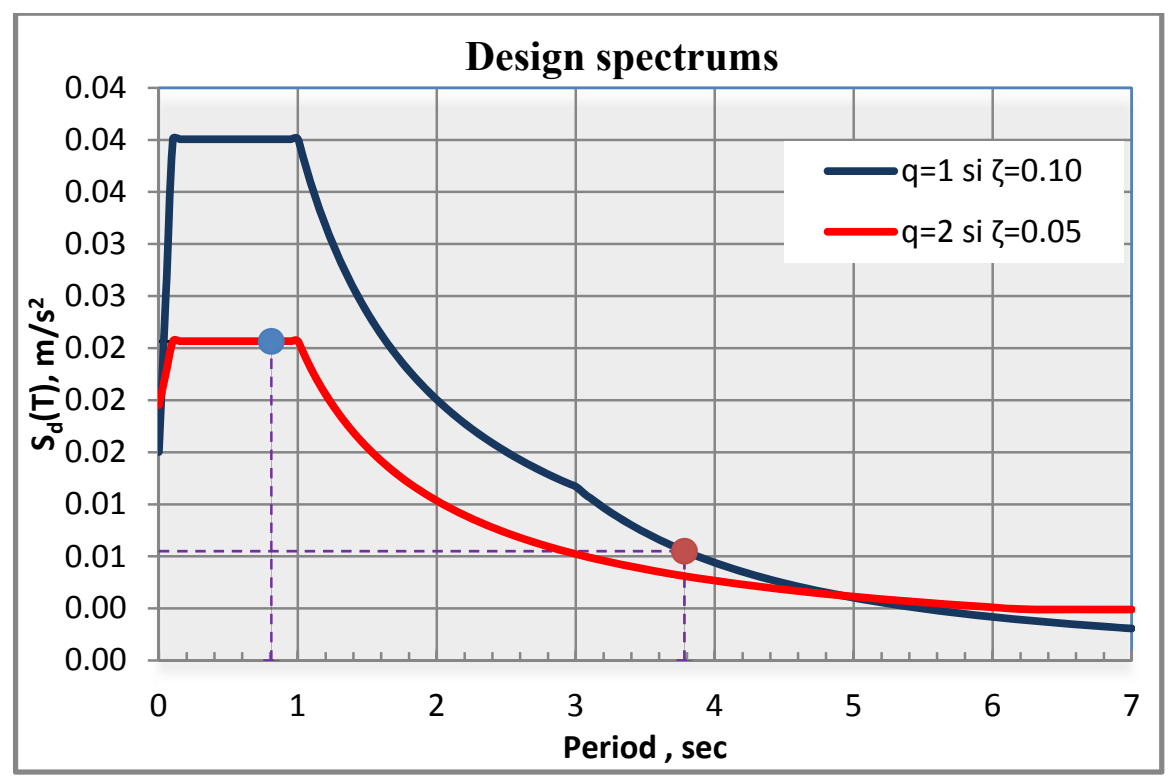

Fig. 9 - Design sprectrums

In the literature, for steel structures with bolted connections it is recommended to adopt the value of $\zeta=0.05$ for fraction of critical damping. Additional damping is introduced by using the isolation system and the manufacturer of the HDRB isolators guaranteed a fraction of critical damping of $\zeta=0.10$. The state of acceleration in the structure decreases from the value of 2.45 $\mathrm{m} / \mathrm{s}^{2}$ corresponding to the classical design, to a value of $0.81 \mathrm{~m} / \mathrm{s}^{2}$ for seismic isolation method.

The maximum displacement at the top of the structure under seismic action is about $\delta=539.3 \mathrm{~mm}$. The base shear force resulted from seismic action is about $F_{b}=3937 k N$. Special devices were additionally introduced near each isolator, which have sufficient stiffness to take the maximum lateral forces caused by the dynamic action of the wind - fig 6. In case of a major seismic event, the capacity of the special wind devices will be overcomed and this will activate the isolation layer. Due to the overturning moment of the storage cell during seismic action, tensile forces are developed in the isolators that have the maximum value of $F_{\text {int }}=471.2 \mathrm{kN}$. This tensile force is in opposition with the weight of the shell, the stored material and the load on the silo roof. Thus, by placing the isolation layer under the storage cell, the tensile forces that can cause fragile failures do not occur in this situation. The maximum compressive force on the isolators has a value of $F_{c, \max }=3813 \mathrm{kN}$. The total weight of the steel support structure in the base isolation method is about $G_{s} \approx 140$ tons. 


\section{Engineering features of the isolators}

The isolators that were used are HDRB isolators with a diameter of $D=850 \mathrm{~mm}$. The diameter of the interior rubber plate is $D^{\prime}=D-10 \mathrm{~mm}=840 \mathrm{~mm}$. This isolator is made up of 26 rubber layers with a thickness of $t_{R}=8 \mathrm{~mm}$, between which steel plates with a thickness of $t_{s}=3 \mathrm{~mm}$ are intercalated. The total thickness of the rubber layer is $T_{q}=208 \mathrm{~mm}$ and the total height of the isolator is $\mathrm{T}_{\mathrm{b}}=393 \mathrm{~mm}$. The shear modulus of the isolator is about $G=0,4 \mathrm{~N} / \mathrm{mm}^{2}$ and the area of the rubber layer is $A=554177 \mathrm{~mm}^{2}$. The following value was obtained for the horizontal stiffness of the isolator:

$K_{r}=K_{e f f}=\frac{G \cdot A}{T_{q}}=1,09 \frac{k N}{m m}$

The shape factors have the following values: $S_{1}=26,25$ and $S_{2}=4,03$. The elastic compression modulus $E_{c}$ ' is determined as follows:

$$
E_{c}^{\prime}=3 \cdot G \cdot\left(1+2 S_{1}^{2}\right)=1655 \mathrm{~N} / \mathrm{mm}^{2}
$$

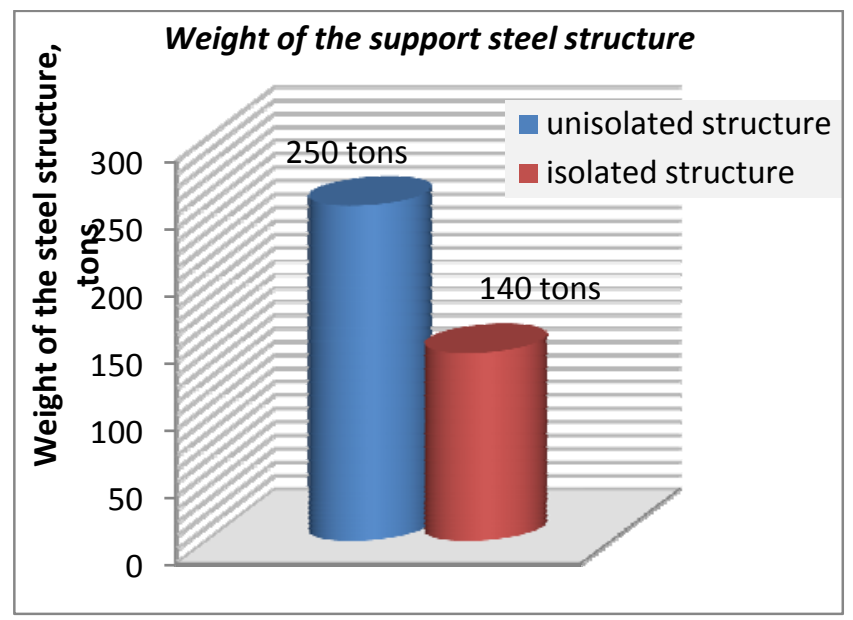

Fig. 10 - Comparison chart in term of the steel amount

\section{Comparative analysis}

Through the insertion of the isolating layer under the storage cell, the structure became more flexible, the fundamental vibration period of increase of 4.68 times and the acceleration decrease with about $68 \%$ - figure 9 .

Due to the decrease of accelerations state felt by the structure, the state of stress of the structural elements also decreases. Thus, the seismic isolation of storage cell mass provides a reduction in the amount of steel required with $44 \%$ - figure 10.

For the unisolated structure, the behavior factor was considered $q=2$ and for isolated structure was adopted $q=1$. Due to the flexibility of structure, although for the isolated structure the behaviour factor has a higher value, the base shear force decreases with $58.6 \%$ - figure 11 .

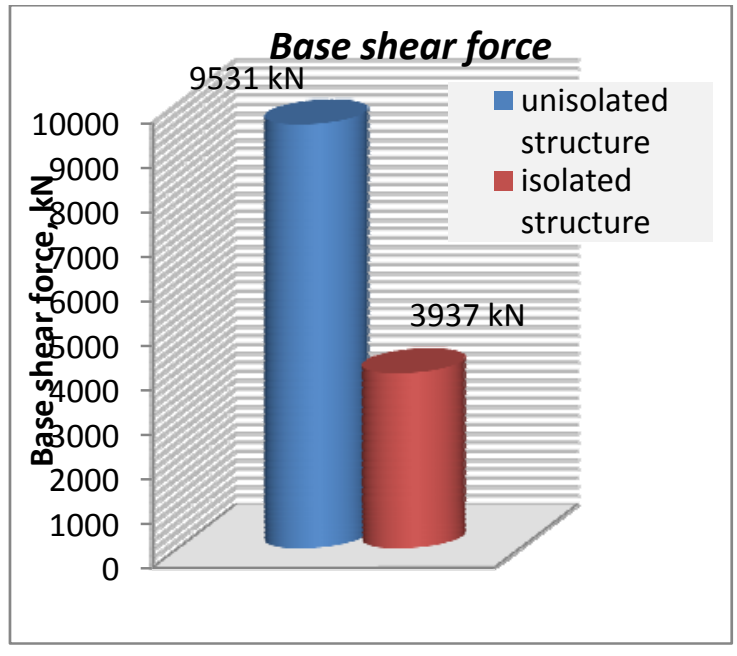

Fig. 11 - Comparison chart in terms of base shear force, $\mathrm{F}_{\mathrm{b}}$

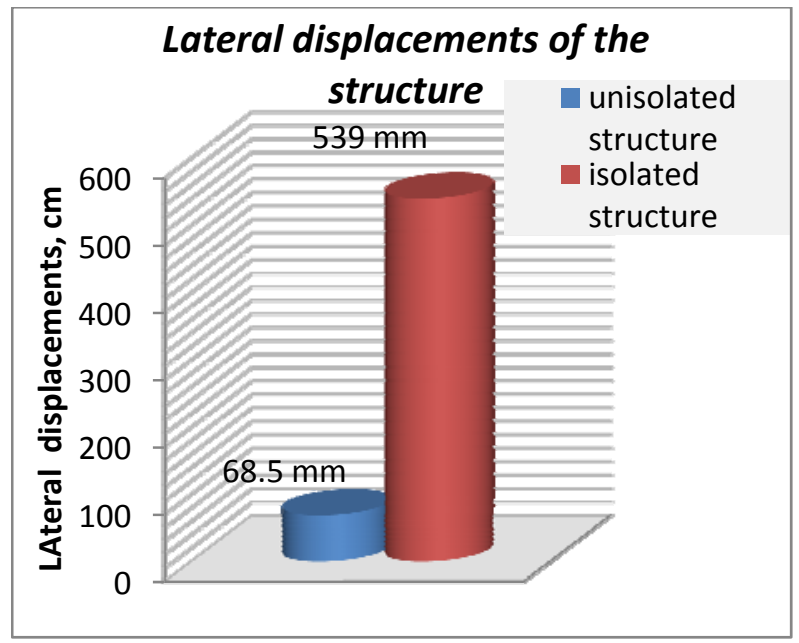

Fig. 12 - Comparison chart in terms of lateral diplacemnts, $\delta_{\mathrm{s}}$ 
The main disadvantage of the seismic isolation method is the high values of lateral displacements. By the seismic isolation the lateral displacement at the top of the structure is increased about 7.8 times - figure 12 .

\section{Conclusions}

The seismic isolation method is a modern method of reducing the structural response due to seismic action. In this method the isolation system can be located at the base of the structure, in the majority of cases, and to isolate only a certain part of the total mass, in particular cases.

The use of this method, due to the flexibility of the structure, leads to significant reduction of the structure acceleration and to reduced effects of the seismic action and by consequence the amount of the used materials is reduced. A major disadvantage of this method, which limits its use, is that it has large lateral displacements. Throughout the entire seismic motion free deformation of the isolation layer should be allowed. A special attention should be given to the arrangement of the isolation system components to avoid torsion.

Seismic isolation method may involve a higher initial cost compared to the classical method, but post-earthquake intervention is more simple, quick and limited to the isolation system, allowing the continuous operation of the structure.

\section{References}

[1]. P100-1 (2013).Seismic Desin Code. Part I - Provisions for buildings.

[2]. CR 1-1-4 (2012). Design code: Wind action on strutures.

[3]. SR EN 1993-1-1 - Eurocod 3: Design of steel structures-Part 1-1:General rules and rules for buildings, CEN.

[4]. http://www.csiamerica.com/sap2000

[5]. http://www.alga.it/

[6]. Yanke, H. Fujita, S. Masaki, N \& Ohta, M.(1992). Development of seismic system for ambient micro-vibration and earthquake using multi-stage rubber bearings and high damping rubber damper, Tenth World Conference of Earthquake Engineering, Rotterdam.

[7]. Naein, F. and Kelly, J. M. (1999). Design of isolated structures. John WILEY \& Sons, New-York.

[8]. Kircher C.A. Seismically Isolated Structures, Chapter 11 of Guide to the Application of the 2000 NEHRP.

[9]. Kelly T.E. (2001). Base insulation of structures: Design guideline, WellingtoN.

[10]. Oprişoreanu V.V. (2012). Contribution in the implementation of the base isolation method for Romania, Ph.D. thesis, UTCB.

[11]. Bitca D., Ursu E., Ioan P. (2013). The concept of base isolation applied to a silo steel structure, a XIII-a Conferinta Nationala de Constructii Metalice, Bucuresti. 